\title{
Hemostatic agents in periapical surgery: The systematic review
}

\author{
(C) Z.S. Khabadze', D.A. Nazarova', E.S. Shilyaeva', A.P. Kotelnikova', Yu.A. Bakayev, S.M. Abdulkerimova', Kh.O. Omarova ${ }^{2}$ \\ ${ }^{1}$ Federal State Autonomous Educational Institution of Higher Education Peoples Friendship University of Russia \\ (RUDN University), Medical Institute, Moscow, Russia \\ ${ }^{2}$ National Medical Research Center of Dentistry and Oral and Maxillofacial Surgery, Moscow, Russia \\ ${ }^{3}$ Dagenstan State Medical University, Makhachkala, Russia
}

\section{Abstract:}

Several agents have been used to secure hemostasis during periapical surgery. Their efficacy, biological response and side effects differ from each other.

Aim. of this review article is to assess systematically the available scientific evidence about the clinical response after using hemostatic agents during apical surgery.

Materials and methods. The study of publications was produced in the electronic databases such as Google Scholar, PubMed during a systematic review of the literature. Included articles contain information about using hemostatic agents during periapical surgery and their adverse effects. The publication date criterion was selected from January 2006 to September 2021.

Results. 55 articles were viewed during the review. After analyzing the literature for inclusion criteria, the total number of publications has become 10.

Conclusions. According to literature data, different hemostatic agents are used during periapical surgery, but there weren't any inflammatory reactions while using calcium sulfate.

Keywords: hemostatic agents, periapical surgery, ferric sulfate, aluminum chloride, epinephrine, calcium sulfate.

Received: 01.06.2021; revised: 13.08.2021; accepted: 19.08.2021.

Conflict of interests: The authors declare no conflict of interests.

For citation: Z.S. Khabadze, D. A. Nazarova, E.S. Shilyaeva, A.P. Kotelnikova, Yu. A. Bakayev, S.M. Abdulkerimova, Kh.O. Omarova. Hemostatic agents in periapical surgery: The systematic review. Endodontics today. 2021; 19(3):184-187. DOI: 10.36377/1683-2981-2021-19-3-184-187.

\section{INTRODUCTION}

Apical surgery is a procedure performed to remove lesions around the apex of a tooth with the main aim of preserving it [15]

For good clinical results and the success of apical surgery, adequate bleeding control is essential, since it improves visualization of the surgical site, minimizes the operating time, and is a requirement for the insertion of most retrograde filling materials [5]. An ideal hemostatic agent for endodontic microsurgery must have a quick hemostatic effect, must be easy to handle, should be biocompatible, and must not undermine natural bony crypt healing and the surrounding tissues [9]. Also biologic stability is an important requirement of local hemostatic agents, because they are placed in direct contact with periapical tissues, including cortical and cancellous bone, soft tissue flap. That's why ina ppropriate application of local hemostatic agent in such area could result in undesirable local tissue response and systemic complications [16].

\section{MATERIALS AND METHODS}

\section{Eligibility Criteria}

Publications that met the following selection criteria were included:

1) Publication year isn't earlier than 2006.

2) Availability of studies proving the properties of each selected material (ferric sulfate, aluminum chloride, epinephrine, calcium sulfate).

3) Figuring the topic of the effectiveness of using ferric sulfate, aluminum chloride, epinephrine, calcium sulfate during periapical surgery and their difference.
The review didn't include publications, the title and abstract of which did not meet at least one of the presented inclusion criteria.

\section{Information So urces}

Up-to-date information in English from Google Scholar, PubMed electronic databases has been studied.

\section{Search and Selection of Studies}

A search in English with no time limit was performed by one person. Search terms included "ferric sulfate", "hemostatic agents", "aluminum chloride", "periapical surgery", "epinephrine", "calcium sulfate".The studies were filtered and selected in several stages. Firstly, they were evaluated by titles. Secondly, individual documents at the first stage were additionally assessed by reading the abstracts and fulltext articles. The first selection criterion was the selection of publications whose titles included at least one search term. Further, publications whih are dated earlier than 2006 were excluded. At the last stage, the content of the full-text versions of the selected articles was examined (Figure 1).

\section{Risk of Bias Assessment}

Cochrane Collaboration data were used to assess the risk of bias, with tests performed at each of the selection stages, according to Higgins et al [30]. The levels of bias were classified as follows: low risk, if all the criteria were met; moderate risk, when only one criterion was missing; high risk, if two or more criteria were missing; and unclear risk, if there were very few details to make a judgement about a certain risk assessment. 


\section{RESULTS}

55 articles were reviewed, of which 15 were from the PubMed database, 40 were from Google Scholar. After the selection according to the exclusion criteria, the total number of articles was 10 . In the selected articles, the relevant data on the effectiveness and side effects of different hemostatic agents were analyzed (Table 1).

\section{DISCUSSION}

Obtaining hemostasis in the surgical crypt during periradicular surgery is essential. It allows for improved visibility and contributes to a dry environment suitable for the placement of moisture-sensitive root-end filling material [4].

Several hemostatic agents has been used in endodontic surgery for many years, like aluminum chloride, ferric sulfate, epinephrine, calcium sulfate. An ideal hemostatic agent for apical surgery should achieve hemostasis within a short period, be easy to manipulate, be biocompatible, not impair or retard healing, and be relatively inexpensive and reliable [13].

\section{Aluminum chloride}

The percentage of the effectiveness in bleeding control was over 90\% in the Expasyl group [5].

Expasyl, a paste containing aluminum chloride and kaolin which is commonly used to produce gingival retraction. Expasyl alone or in combination with ferric sulfate appeared to be the most efficient agent, and the inflammatory tissue reactions were limited to the bone defects, never extending into the surrounding tissues. Though swelling is more pronounced in the Expasyl group [3]. Adverse reactions to Expasyl did not occur if the traces of the paste were eliminated from the bone crypt with rotary instruments.

Expasyl + Stasis $\AA^{\circledR}$ and electro cauterization proved most effective in reducing bleeding $(P<0.05$ ), but were accompanied by unfavourable tissue reactions, as indicated by the presence of necrotic bone, inflammatory cells and the absence of bone repair. These adverse tissue reactions did not recover substantially over time [8].

\section{Ferric sulfate}

The percentage of the effectiveness in bleeding control was $60 \%$ in the ferric sulfate group [15].

Ferric sulfate is one of the mostcurrently used hemostatic agents in apical surgery. The mechanism of action of ferric sulfate is chemical, producing the coagulation of proteins, so it acts in a similar way to cauterization [13].

When applied on bleeding spot, ferric sulfate immediately forms dark-brownish clot without additional pressure, and the hemostas is could be maintained up to 5 minutes. Therefore, ferric sulfate should be applied in bone cavity to a minimum extent. It is recommended to apply FS only on small bleeding points of cortical bone surface. Also it should be noted that ferric sulfate also interferes soft tissue healing. Ferric sulfate revealed less

\section{5 publications in PubMed and Google Scholar}

Publications after removing duplicates $(n=46)$.

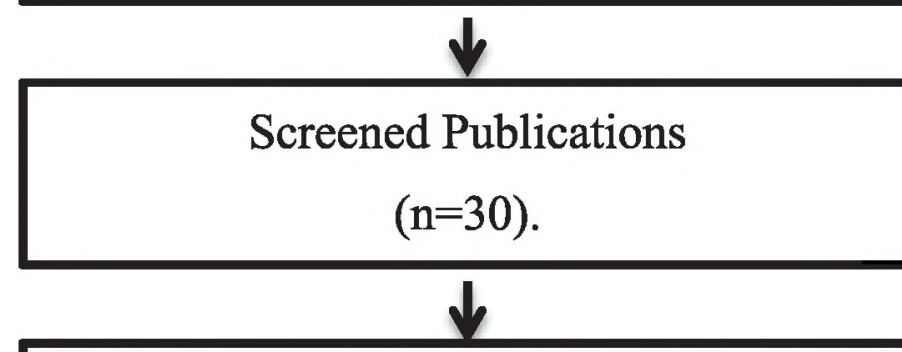

Full-text articles rated for eligibility $(n=22)$.

$$
(\mathrm{n}=12)
$$

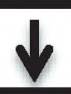

Studies included in the review

$$
(\mathrm{n}=10)
$$

Fig. 1. Article selection process. 


\section{$186 \mid$ обзоры / Reviews}

Table 1. Characteristics of the studies included in the review.

\begin{tabular}{|l|c|c|c|l|}
\hline \multicolumn{1}{|c|}{ Author } & $\begin{array}{c}\text { Publication } \\
\text { year }\end{array}$ & Study & Number & \multicolumn{1}{|c|}{ The material } \\
\hline Antonio S. et al [2] & 2012 & Patients & 24 & CaS, ferric sulfate \\
\hline Peñarrocha-Diago M. et al [3] & 2012 & Patients & 96 & Vasoconstrictor, aluminium chloride \\
\hline Azargoon H. et al [4] & 2011 & Rabbits & 12 & HemCon, ferric sulfate \\
\hline Jensen S.S. et al [8] & 2010 & Bone defects & 6 & Expasyl, epinephrine \\
\hline David P. O. et al [9] & 2020 & Patients & 30 & Expasyl, epinephrine \\
\hline María P-D. et al [10] & 2018 & Patients & 95 & Epinephrine, aluminium chloride \\
\hline Isabel M- N. et al [14] & 2016 & Patients & 99 & epinephrine, aluminum chloride \\
\hline Mushtaq F. et al [15] & 2020 & Patients & 120 & Vasoconstrictor, aluminum chloride \\
\hline Liqaa S. F. et al [18] & 2017 & Patients & 300 & Collagen sponge, alustat, adrenaline \\
\hline Mc Goldrick N. et al [19] & 2017 & Patients & 120 & Epinephrine, aluminium chloride \\
\hline Penarrocha D. M. et al [20] & 2019 & Bone defects & 72 & CaS, Gelatamp, Hemocor \\
\hline Peñarrocha- Oltra D. et al [26] & 2019 & Patients & 30 & Epinephrine, aluminum chloride \\
\hline
\end{tabular}

hemostatic efficacy than topically-applied epinephrine [16].

The use of ferric sulfate as necrotizing material with an extremely low $\mathrm{PH}(0.21)$ causes very good homeostasis through rapid intravascular coagulation. Nevertheless, the risk of use of ferric sulfate in contact with important anatomic structures such as maxillary sinus, floor of the nose, or mandibular and mental nerve limits its clinical usage. In addition, failure to adequate curettage and irrigation of the surgical site after ferric sulfate application can lead to foreign body reaction, impaired healing, and abscess [11]. The result with using ferric sulfate as hemostatic agent is normal healing with a slight foreign body reaction after curetting the cavity thoroughly and irrigating with saline.

\section{Epinephrine}

Epinephrine has been recommended as effective local hemostatic agent in endodontic surgery [15]. Epinephrine produces vasoconstriction by stimulation of a-adrenergic receptors. Adverse local tissue reaction are because of its strong vasoconstrictive effect, also epinephrine has been associated with local tissue ischemia and subsequent tissue necrosis on gingiva, bone tissues, and sensory nerve. Epinephrine strongly stimulates cardiac function by increasing both cardiac output and pulse rate when it is bound to $\beta 1$ - receptor. Thus, epinephrine is closely related to alteration of cardiovascular function when it enters systemic circulation [16].

Collagen sponges saturated with epinephrine provided excellent bleeding control without changes in blood pressure or heart rate [13].

The healing percentages after 12 months was $91.4 \%$ in the group treated with dressings impregnated with anesthetic solution and vasoconstrictor [5].

Spongostan + epinephrine showed only a moderate haemostatic effect, but elicited also only mild adverse tissue reactions [8].

\section{Calcium sulfate}

The percentage of the effectiveness in bleeding control was $100 \%$ in the calcium sulfate group [15].

The advantages of using calcium sulfate are excellent biocompatibility, resorbability and inexpensive price. It is recommended for application when the size of the periapical bony crypt is large. Calcium sulfate is reported to be positively related to growth factor release (BMP-2, BMP-7, TGF- $\beta$, and PDGF), angiogenesis and fibroblast migration, which could enhance bone healing [16]. Calcium sulfate remained around the apex after the completion of surgery, there would not have been any complications due to its biocompatibility and its resorbability [31].

\section{CONCLUSION}

Hemostasis control is an essential element in endodontic surgery, ensuring a proper environment for retrograde filling; it affords better visibility of the surgical field improves ergonomics and contributes to lessen postsurgical bleeding and swelling.

Several hemostatic agents, like calcium sulfate, ferric sulfate, epinephrine, aluminium chloride, are used during periapical surgery, They have different structure, mechanism of action, local and body reactions. That's why, their effectiveness, side effects and percentage of success in bleeding control differ from each other.

The percentage of effectiveness is the highest in calcium sulfate group. Due to the lack of biologically negative effects, its biocompatibility and good clinical response, calcium sulfate could be used as hemostatic agent in periradicular surgery.

There was also good effectiveness using aluminium chloride and epinephrine. However, the postoperative swelling was more significantly observed in patients with aluminum chloride. Epinephrine have demonstrated good hemostatic effiicacy without foreign body reactions if it doesn't enter systemic circulation.

The ferric sulfate group's effectiviness was lower than in other groups. Also the tissue damage produced when the superficial bone layer was not removed and its relation to the prognosis must be considered during using this hemostatic agent in apical surgery.

The hemostatic agents that have obtained the best results are ferric sulfate, calcium sulfate, aluminum chloride and epinephrine.

\section{SUMMARY}

Hemostatic agents which achieve good hemostasis without foreign body reactions are calcium sulfate and epinephrine. Ferric sulfate and aluminium chloride are also have good hemostatic effect, however, their usage can lead to foreign body reaction and postopertaive swelling. 


\section{REFERENCES:}

1. Von Arx T, Jensen SS, Hänni S, Schenk RK. Haemostatic agents used in periradicular surgery: an experimental study of their efficacy and tissue reactions. Int Endod J. 2006;39:800-8.

2. Antonio S, Luciano A, Adriano P, Francesco C, Carlo M, Giovanna I. Hemostasis control in endodontic surgery: a comparative study of calcium sulfate versus gauzes and versus ferric sulfate. J Endod. 2012 Jan;38(1):20-3

3. Peñarrocha-Diago $M$, Maestre-Ferrin $L$, Peñarrocha-Oltra $D$ Gay-Escoda C, von-Arx T, Peñarrocha-Diago M. Pain and swelling after periapical surgery related to the hemostatic agent used: anesthetic solution with vasoconstrictor or aluminum chloride. Med Oral Patol Ora Cir Bucal. 2012;17:e594-600.

4. Azargoon H, Williams BJ, Solomon ES, Kessler HP, He J, Spears R Assessment of hemostatic efficacy and osseous wound healing using HemCon dental dressing. J Endod. 2011;37:807-11.

5. Peñarrocha-Diago $M$, Maestre-Ferrîn $L$, Peñarrocha-Oltra $D$, von Arx T, Peñarrocha-Diago M. Influence of hemostatic agents upon the outcome of periapical surgery: dressings with anesthetic and vasoconstrictor or aluminum chloride. Med Oral Patol Oral Cir Bucal 2013;18:e272-8

6. Orrett E. O, Jason S, Amandip K. Hemostatic agents. Dent Clin North Am. 2011 Jul;55(3):433-9

7. Am andip K, Jason S. Hemostasis in oral surgery. Dent Clin North Am. 2012 Jan;56(1):17-23

8. Jensen S.S, Yazdi P.M, Hjørting-Hansen E, Bosshardt D.D, von Arx $T$. Haemostatic effect and tissue reactions of methods and agents used for haem orrhage control in apical surgery. Int Endod J. 2010;43:57-63.

9. David P-O, David S-P, Miguel P-D, Juan C-B, Guillerm o C-G, María $P$-D. Hemostatic agents in endodontic surgery of maxillary molars: $A$ randomized controlled pilot study of polytetrafluoroethylene (PTFE) strips as an adjunct to epinephrine impregnated gauze versus alum inum chloride. Med Oral Patol Oral Cir Bucal. 2020 Sep; 25(5): e634-e643.

10. María P-D, Isabel M-N, Juan C-B, Laura M-F, Juan A. B-T DavidPeñarrocha-O. Influence of Hemostatic Agents in the Prognosis of Periapical Surgery: A Randomized Study of Epinephrine versus Aluminum Chloride. Journal of Endodontics. Vol 44, Issue 8, August 2018, Pages 1205-1209

11. Mohammad R. N, Arman Z, Fariborz M, Fatemeh A, Safoora S Alireza F, Pouya F. Comparison of the Hemostatic Activity of Quercus persica Jaub. \& Spach. (Oak) With Ferric Sulfate in Bony Crypts. J Evid Based Complementary Altern Med. 2016 Jan;21(1):34-8

12. David P-Ol, Isabel M-N, Juan C-B, Laura M-F, Miguel P-D, Marı P-D. Aluminum Chloride versus Electrocauterization in Periapica Surgery: A Randomized Controlled Trial. Journal of Endodontics. 2019, 45(2): $89-93$

13. Menéndez Nieto I, Cervera Ballester J, Peñarrocha Diago $M$, Peñarrocha Oltra D. New perspectives in periapical surgery Hemostasis. J Oral Science Rehabilitation. 2018 Sep;4(3): 46-49

14. Isabel M-N, Juan C-B, Laura M-F, Juan A. B-T, David P-O, Miguel P-D. Hemostatic Agents in Periapical Surgery: A Randomized Study of Gauze Impregnated in Epinephrine versus Alum inum Chloride. J Endod. 2016 Nov;42(11):1583-1587.

15. Mushtaq F, Mushtaq U. Usage of aluminum chloride for hemostasis vs anesthetic solution in periapical surgery. J Adv Med Dent Scie Res. 2020;8(5):169-173.

\section{AUTHOR INFORMATION:}

Zurab Khabadze' - Candidate of Medical Sciences, Associate Professor of Department of Therapeutic Dentistry, ORCID ID: 0000-0002-7257-5503.

Daria Nazarova' - student.

Ekaterina Shilyaeva ${ }^{1}$ - student.

Alexandra Kotelnikova ${ }^{1}$ - student.

Yusup Bakayev ${ }^{2}$ - resident student.

Saida Abdulkerimova ${ }^{2}$ - resident student.

Khadizhat Omarova ${ }^{3}$ - Ph.D, Head of the Department of Propaedeutic and Preventive Dentistry.

1 "Peoples' Friendship University of Russia" (RUDN University), Moscow, Russia

${ }^{2}$ National Medical Research Center of Dentistry and Oral and Maxillofacial Surgery, Moscow, Russia

${ }^{3}$ Dagenstan State Medical University, Makhachkala, Russia.
16. Youngjune J, Hyeon K, Byoung-Duck R, Euiseong K. Biologic response of local hemostatic agents used in endodontic microsurgery. Restorative Dentistry \& Endodontics. 2014; 39(2): $79-88$.

17. Jang $Y$, Kim E. Cardiovascular effect of epinephrine in endodontic microsurgery: a review. Restor Dent Endod. 2013; 38:187-193.

18. Liqaa S. F. Experimental study to evaluate the effect of topical hemostatic agents on healing of bone defects after endodontic microsurgical procedures. International Journal of Dental Sciences and Research. 2017, Vol. 5, No. 4, 93-97

19. Mc Goldrick N, Ross C, Nelson J. Trial finds better haemostasis with aluminium chloride during periapical surgery. Evid Based Dent $017,18,50-51$

20. Mena-Álvarez J, Quispe-Lopez N, Zubizarreta-Macho Á, RicoRomano C, Rodero-Villanueva R, Fernández-Aceñero MJ. Histological analysis of different local haemostatic agents used for periapical surgery: An experimental study with Sprague-Dawley rats. Aust Endod

21. Phum patrakom $P$, Ariyakriangkai $W$, Srisuwan $T$, Louwakul $P$. In vitro cytotoxicity of some hemostatic agents used in apicoectomy to

22. Bandi M, Mallineni SK, Nuvvula S. Clinical applications of ferric sulfate in dentistry: A narrative review. J Conserv Dent. 2017;20(4):278-

23. Ogle O.E, Swantek J, Kamoh A. Hemostatic agents. Dental ics of North America. 2011 Jul:55(3):433-9

24. Penarrocha D. M, Ortega S. B, Garcia M. B, Marti B. E, von ArX Gay $E$. C. Evaluation of healing criteria for success after periapical urgery. Med Oral Patol Oral Cir Bucal. 2008;13:E143-7.

25. Ravindranath $M$, Alagarsamy $V$, Rathakrishnan $M$ akshinamoorthy $M$. An overview of materials used in periapical surgery. European Journal of Molecular \& Clinical Medicine, 2020; 7(10): $631-636$

26. Peñarrocha-Oltra $D$, Soto-Peñaloza $D$, Peñarrocha-Diago $M$ Cervera-Ballester J, von Arx T, Peñarrocha-Diago M. Hemostatic Agents in Endodontic Surgery: A Randomized Controlled Pilot Study of Polytetrafluoroethylene Strips as an Adjunct to Epinephrine Impregnated Gauze Versus Aluminum Chloride. J Endod. 2019 Aug;45(8):970-976

27. Mehta V, Bhatia V, Aggarwal A. A review on chemical hemostatic agents in dentistry. Guident. 2016, Vol. 9 Issue 7, p52-54. $3 p$.

28. Amit M, Raju A, Preeti $K$, Shalakha M, Sekharmantri A. Hemostatic Agents in Dentistry. Galore International Journal of Health Sciences and Research. 2018, Vol.3; Issue 4; p40-46

29. Kamoh A, Swantek J. Hemostasis in oral surgery. Dent Clin North Am. 2012; 56(1):17-23

30. Higgins J.PT, Altman D.G., Gotzsche P.C, Juni P. Moher D. Oxman A.D. Savovic J Schulz K.F. Weeks L, Sterne J.A. The Cochrane Collaboration's tool for assessing risk of bias in randomised ials. BMJ. 2011;343

31. Sinjab Y.H, Sinjab K.H, Navarrete-Bedoya C, Gutmann J.L. Calcium sulfate applications in dentistry: A literature review. Endodontology. 2020:32:167-74 J. 2019 Dec;45(3):357-364. 